\title{
Can permanent cell lines originate from low-grade astrocytomas: overgrowth of "glia-like“ cells in pilocytic and fibrillary (diffuse) astrocytoma cultures
}

\author{
Sivakova I, Mraz P, Kubikova E, El Falougy H, Perzelova A \\ Department of Anatomy, Faculty of Medicine, Comenius University, Bratislava, Slovakia. \\ Anna.perzelova@fmed.uniba.sk
}

\begin{abstract}
OBJECTIVES: Due inter alia to wide-spread cell lines cross-contamination it is not clear, which kind of normal or tumoral tissue give rise to permanent cell lines.

BACKROUND: Few permanent cell lines have been established from low-grade astrocytomas. However, recently some of these have been identified as being cross-contaminated with other cell lines.

METHODS: Morphology, cell growth and GFAP immunophenotype of low-grade astrocytomas were examined on 9 pilocytic and 15 fibrillary (diffuse) tissue cultures.

RESULTS: GFAP-positive process-bearing cells were present in all the cultures, mainly during the first days in vitro (DIV). In pilocytic cultures, cells with hairy (piloid) processes were present. GFAP-positive cells completely disappeared by passages 3 to 5 and all the cultures contained only GFAP-negative "glia-like" cells, which underwent cellular senescence within passages 8 to 15.

CONCLUSION: Key differences in the morphology and GFAP expression between the neoplastic astrocytes and normal "glia-like" cells allow the observation of perceptibly more rapid growth of normal cells in astrocytoma cultures. We caution that cultures prepared from macroscopically tumoral brain tissue may contain rapidly proliferating normal cells. Based on this and our previous studies in relation to the high percentage of cross-contaminated cell lines, we conclude that cells in low-grade astrocytoma cultures lack the capacity for spontaneous immortalization (Fig. 14, Ref. 15). Text in PDF www.elis.sk KEY WORDS: pilocytic astrocytoma, fibrillary astrocytoma, "glia-like" cells, glioma cell lines, GFAP.
\end{abstract}

\section{Introduction}

Astrocytomas are the type of primary brain tumours that arises from star-shaped glial cells called astrocytes. They are classified according to the grading system developed by the World Health Organization (WHO), which was updated (4th edition) in 2007 (1). The 2016 WHO classification of the CNS is the restructured CNS tumour classification using molecular parameters in addition to histology (2). Astrocytomas come in four grades based upon how quickly they proliferate and infiltrate adjacent brain tissue: namely, grade I (pilocytic astrocytoma), grade II (diffuse astrocytoma: fibrillary, protoplasmic and gemistocytic), grade III (anaplastic astrocytoma), and grade IV (glioblastoma). Grades I and II astrocytomas are the slowest growing tumours, also called low-grade gliomas, while grades III and IV are high-grade malig-

Department of Anatomy, Faculty of Medicine, Comenius University, Bratislava, Slovakia

Address for correspondence: A. Perzelova, Department of Anatomy, Faculty of Medicine, Comenius University, Sasinkova 2, SK-813 72 Bratislava, Slovakia.

Acknowledgements: This study was supported by VEGA grant No. 1/3439/06 and ITMS: 26240120023, co-financed by the European Regional Development. nant gliomas. Tumour grade is the key factor influencing the treatment strategies and also providing information about prognosis.

Fibrillary astrocytomas are the most common type of lowgrade gliomas in adults that occur anywhere in the brain. They are distinctive with a diffuse growth into surrounding normal brain tissue, so they are also named diffuse astrocytomas. An important feature of these tumours is their progress into anaplastic astrocytoma or glioblastoma. Pilocytic astrocytomas are most often found in children in the first decade of life and are located mainly in the cerebellum and chiasmatic/hypothalamic region. They are wellcircumscribed and generally considered as benign tumours $(3,4)$.

Cultures derived from adult human brain tissue are poorly characterized until now and are often termed "glia-like" cells. This term was introduced to cover the predominant population of GFAP-negative cells in brain cultures (5). Recently, we demonstrated the presence of "glia-like“ cells in short-term glioblastoma cultures (6). Here, we characterize the cultures from low-grade astrocytomas occurring in adults and children.

\section{Materials and methods}

\section{Glioma specimens and tissue cultures}

Glioma samples with a low and high WHO grade of malignancy were kindly provided by the Department of Neurosurgery, 


\section{7-370}

Derer's Hospital, Bratislava. They were collected between 1993 to 2011. Experiments with human brain biopsies were performed according to Slovak laws 272/1994, 76/2004, and approved by the Ethical Committee of UNB Bratislava.

We cultured and examined low-grade gliomas. In this study we examined 9 cultures derived from pilocytic astrocytomas grade I (patients aged 4 to 16) and 15 cultures from fibrillary (diffuse) astrocytomas grade II (patients aged 28 to 61). Bioptic samples were cut into small pieces (explants) and seeded into uncoated plastic dishes $\left(25 \mathrm{~cm}^{2}\right)$. Culture medium consisted of MEM with glutamine, nonessential amino acids and $10 \%$ foetal calf serum (Sigma). Cultures were passaged using 0.2\% EDTA and 0.25\% trypsin. Cells used for immunofluorescence staining were grown under the same conditions on uncoated glass coverslips.

\section{Immunofluorescence}

Indirect immunofluorescence using antibodies to GFAP (clone GF-01, 1:100, Exbio, Prague, and polyclonal sera to GFAP, 1:100 (Dako) was performed in all the cultures in early passages. Cells grown on coverslips were rinsed with PBS, fixed in methanolacetone $(1: 1)$ solution for $15 \mathrm{~min}$ at $-15^{\circ} \mathrm{C}$. Secondary fluorescein-conjugated antibodies were purchased from Sigma. Cells for indirect immunofluorescence were incubated $1 \mathrm{~h}$ with primary and $30 \mathrm{~min}$. with secondary antibodies. Fluorescence microscopy was performed using an Olympus BX51 microscopy (Olympus, Germany).

\section{Cell kinetics}

Proliferation rates were determined in 3 pilocytic and 3 fibrillary astrocytoma cultures between passages 3 to 5 . Growth curves were constructed from the counts of the harvested cells. For counting, we used the cells from two dishes within DIV 1 to 5. Chamber cell counting was accomplished by enumerating 20 marked microscopic fields.

\section{Results}

Morphology and immunofluorescence staining of pilocytic and fibrillary tissue cultures

Morphological properties of cultured glioma cells were examined with an inverse phase-contrast microscopy performed on living cells. All astrocytoma cultures contained neoplastic astrocytes bearing long and thin processes. These cells were specific mainly for fibrillary astrocytomas. They were found as single attached cells or outgrowing from small explants (Fig. 1A, B). Similarly, all the cultures contained spindle or flat "glia-like" cells. Both astrocytoma cultures contained areas of morphologically very heterogeneous cells. Here we demonstrate pilocytic astrocytoma culture at DIV 9 containing explant with astrocytic morphology (Fig. 1C) and a neighbouring explant with outgrowth of "glia-like" cells (Fig. 1D).

The cultures during the passage number 2 were mostly comprised of "glia-like" cells. Rarely there occurred small transported explants with a persistent outgrowing of neoplastic astrocytes (Fig. $1 \mathrm{E})$. Confluent cultures in early passages contained mainly flat cells. Only rarely there occurred astroglial small bipolar astrocytes (Fig. 1F). Astroglia-like cells had completely disappeared between the passage numbers 3 to 5 .

Examination of astrocytoma cultures by immunofluorescence was performed with antibodies to GFAP, considered the best marker
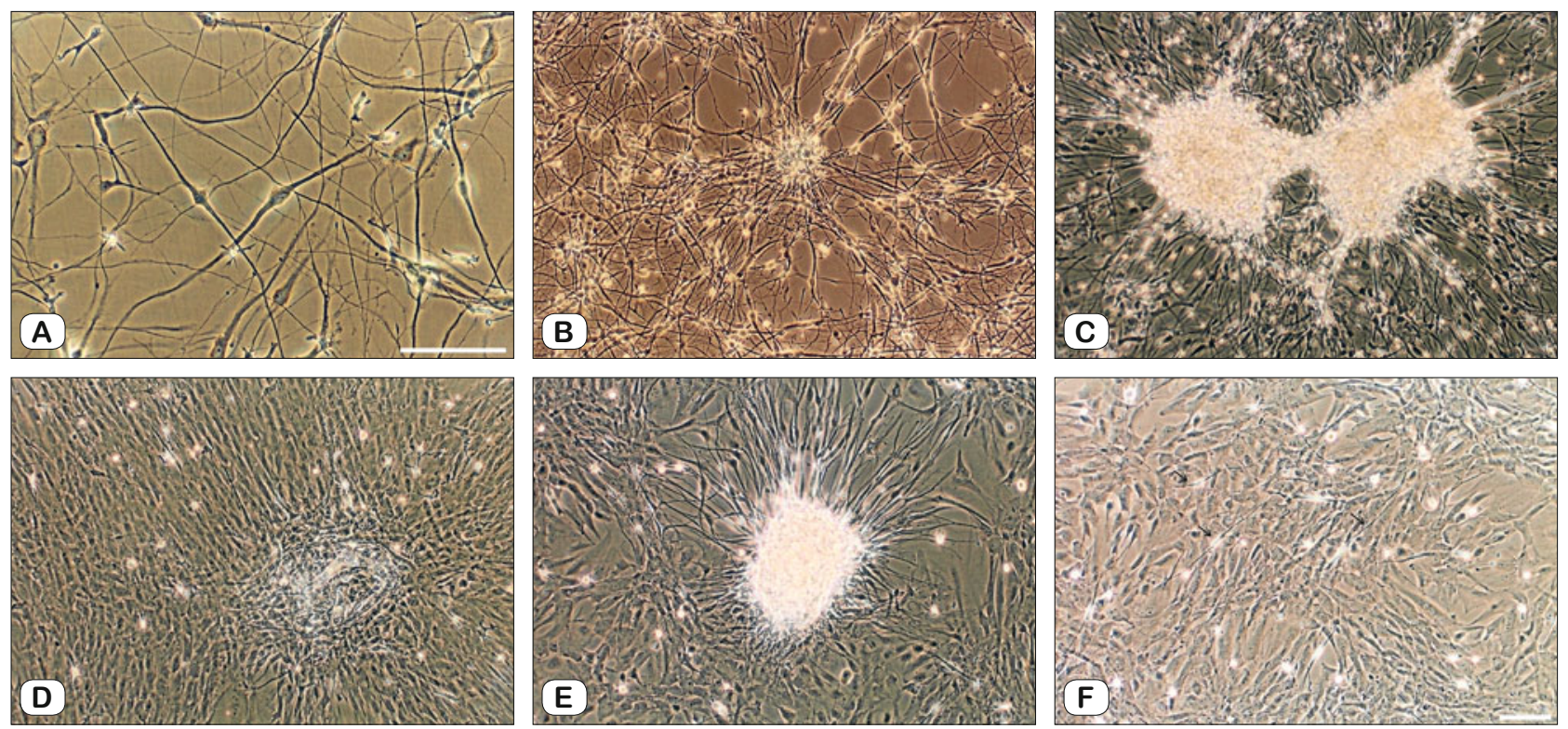

Fig. 1. Morphological properties of living cells, phase-contrast microscopy. Fibrillary astrocytoma cultures: long and thin process-bearing cells, single attached (A) and a small explant at DIV 5 (B). Pilocytic astrocytoma cultures: explants with outgrowing of neoplastic astrocytes at DIV 9 (C) and a neighbouring explant with outgrowing "glia-like" cells (D). The cultures in passage number 2 contained flat "glia-like" cells and small explant with outgrowing of hairy cellular processes (E) or small bipolar cells overlaying flat confluent "glia-like“ cells (F). Scale bars: 100 um. 

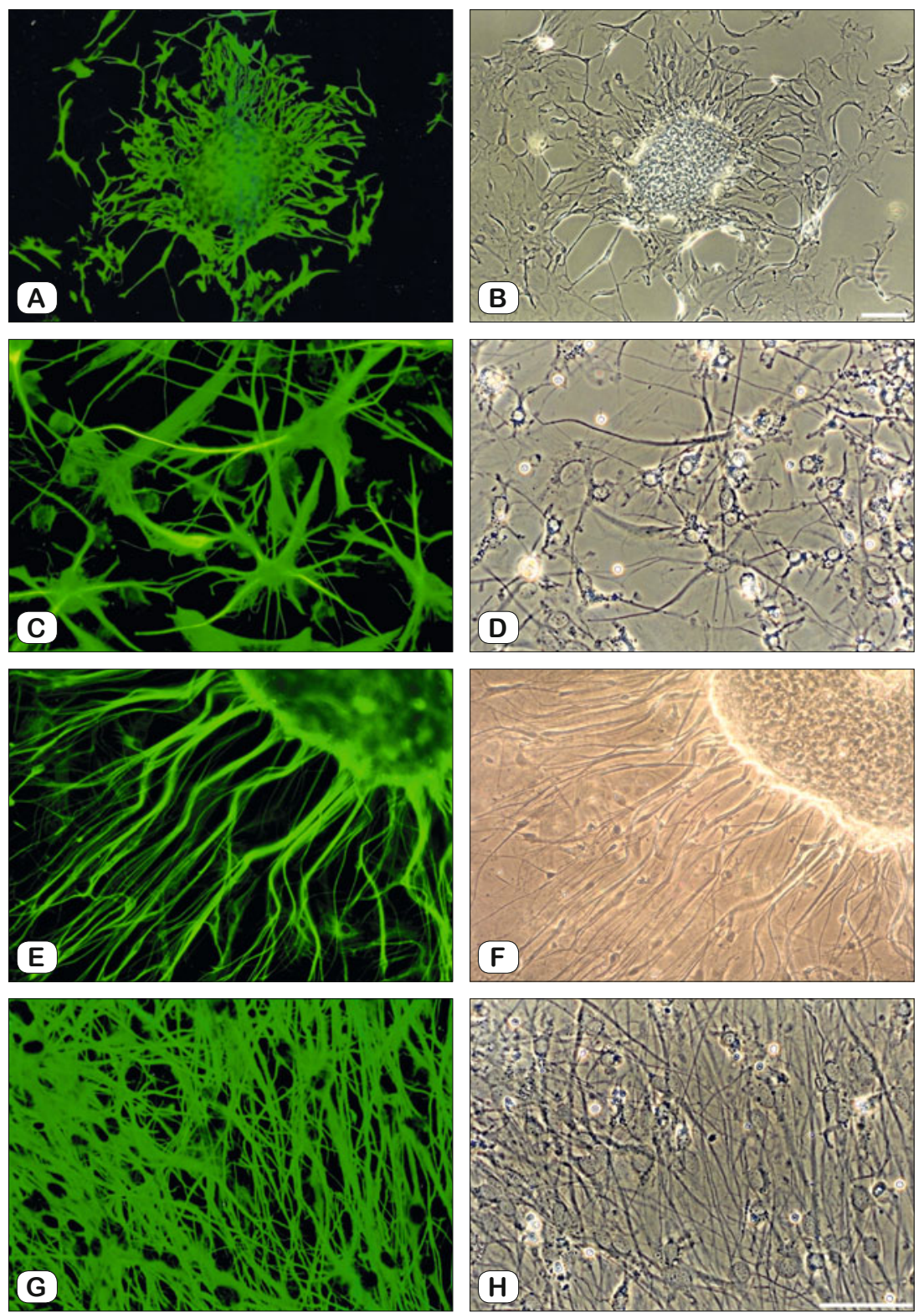

Fig. 2. Indirect immunofluorescence staining for GFAP. Fibrillary astrocytoma cultures: variable morphology of GFAP-positive cells outgrowing from explant and GFAP-negative glia-like cells (A-B), GFAP-positive cells similar to fibrous astrocytes (C-D). Pilocytic astrocytoma cultures: GFAP-positive processes outgrowing from explant (E-F) and cells with hairy processes specific for these tumours (G-H). Scale bars: $100 \mathrm{um}$.

for normal and neoplastic astroglial cells and used for diagnosis of gliomas. Recent studies showed that GFAP expression is influenced by astrocytoma grade and frequently lost with an increasing grade of glioma malignancy $(7,8)$. However, for low-grade glioma, GFAP always remains the best marker. Immunostaining for GFAP was performed in all the cultures and revealed a strong positive staining in all long and thin process-bearing cells. In addition, a variety of different morphological forms of GFAP-positive cells with poorly developed processes were present in a low percentage, mainly in fibrillary astrocytoma cultures (Fig. 2A, B). However, the majority of GFAP-positive cells showed a fibrous astroglial morphology (Fig. 2C, D). Specific for pilocytic astrocytoma cultures was the presence of hairy (piloid) cellular processes (Fig. 2E-H).

\section{Cell growth}

Cells in astrocytoma cultures reached confluency usually within 10 to 15 DIV after explants seeding. Population doubling time determined from the growth curves in three well proliferating fibrillary and pilocytic cultures between the passage 3 to 5 was approximately 24 to 36 hours. Within the passages 8 to 15 , the cells in all the cultures showed a decreased proliferation following by cellular senescence. Any permanent cell growth was observed in these astrocytoma cultures.

\section{Discussion}

In this report, we demonstrate the behaviour of tissue cultures prepared from pilocytic and fibrillary astrocytoma samples. The cultures contained high percentages of GFAP-positive cells bearing long and thin processes within 10 to 15 days after explants seeding. Only small morphological differences were observed between both astrocytoma cultures. In pilocytic cultures, some GFAP-positive cells showed hairy processes. GFAP-negative flat or spindleshaped "glia-like" cells occurred in all the cultures. Similar cells with non-glial phenotypes were found in normal adult human brain cultures $(9,10)$. In addition, we recently demonstrated the presence of normal "glia-like“ cells in glioblastoma cultures (6). Specific morphological features of astrocytic GFAP-positive and flat GFAP-negative cells permit distinguishing between the neoplastic astrocytes and normal "glia-like“ cells. At increased passage number, "glialike“ cells became the predominant cell subpopulation in all the cultures and after the passage number 5 , the cultures contained only "glia-like" cells. All the cultures showed limited life spans and cellular senescence occurred between the passages number 8 to 15 .

A similar explant cultures of astrocytomas of different grades of malignancy has been examined by Kharbanda, 1993 (11). In their cultures, GFAP expression decreased over time in all cultures irrespective of grading. In addition, they revealed the lower BrdU LI in glioblastoma multiforme in comparison to low-grade astrocytomas and suggested un unidentified mechanism underly- 


\section{7-370}

ing cell differentiation. These findings match our observation. However, we explain the above-mentioned decrease in GFAPpositive cells by overgrowth with GFAP-negative "glia-like“ cells, which in early passages may grow even more rapidly than glioma cells (6). Recently, we described the establishment of permanent glioblastoma cell lines in 2 of 30 cultures $(12,15)$. The remaining cultures showed a limited life span and similar properties to low-grade astrocytoma cultures. The presence of "glia-like“ cells in glioma cultures may be explained by the infiltrative growth of astrocytomas and glioblastoma into surrounding brain tissue. However, the cultures derived from well circumscribed pilocytic astrocytoma showed the presence of "glia-like" cells similarly.

Currently, the basic question of permanent cell growth from different cancer and/or normal tissue remains unanswered, largely because the recent studies revealed a high number of normal or cancer cross-contaminated cell lines $(13,14)$. Several permanent cell lines from low-grade gliomas were identified as cross-contaminated mainly by the HeLa and some other classic cell lines (https:// iclacstaging.wpengine.com/databases/cross-contaminations/). In our laboratory, we were able to establish permanent cell lines only from glioblastoma tissue, with a rate of establishment of about $10 \%$ (12), any permanent cell lines established from low-grade astrocytomas. To the best of our knowledge, the authentic permanent cell lines from low-grade astrocytomas have never been reported.

\section{References}

1. Louis DN, Ohgaki H, Wiestler OD, Cavenee WK, Burger PC, Jouvet A, Scheithauer BW, Kleihues P. The 2007 WHO classification of tumours of the central nervous system. Acta Neuropathol 2007; 114: 97-109. DOI: 10.1007/s00401-007-0243-4.

2. Louis DN, Perry A, Reifenberger G, Deimling A, Figarella-Branger D, Cavenee WK, Ohgaki H, Wiestler OD, Kleihues P, Ellison DW. The 2016 world health organization classification of tumors of central nervous system: a summary. Acta Neuropathol 2016. DOI: 10.1007/s00401-0161545-1.

3. Perry A, Wesseling P. Histologic classification of gliomas. 71-95. In: Berger MS and Weller M (Eds). Handbook of Clinical Neurology, Gliomas. Amsterdam: Elsevier, 2016. DOI: 10.1016/B978-0-12-802997-8.00005-0.
4. Bonfield CHM, Steinbok P. Pediatric cerebellar astrocytoma: a rewiew. Childs Nerv Syst 2015; 31: 1677-1685. DOI: 10.1007/s00381-015-2719-1.

5. Ponten J, Westermark B. properties of human malignant glioma cells in vitro. Med Biol 1978; 56 (4): 184-193.

6. Sivakova I, MacLeod R, Mraz P, Kubikova E, Perzelova A. Short term glioblastoma cultures may contain normal "glia-like“ cells. Bratisl Med J 2019; 120 (9): 625-629. DOI: 10.4149/BLL_2019_103.

7. Sereika M, Urbanaviciute R, Tamasauskas A, Skiriute D. GFAP expression is influenced by astrocytoma grade and rs2070935 polymorphism. J Cancer 2018; 9 (23): 4496-4502. DOI: 10.7150/jca.26769.

8. Restrepo A, Smith CA, Agnihotri S, Shekarforousch M, Kongkham PN, Seol HJ, Northcott P, Rutka JT. Epigenetic regulation of glial fibrillary acidic protein by DNAmethylation in human malignant gliomas. Neurooncol 2011; 13 (1): 42-50. DOI: 10.1093/neuonc/noq145.

9. Rutka JT, Kleppe-Hoiford H, Emma DA, Giblin JR, Dougherty DV, McCulloch JR, DeArmond SJ, Rosenblum ML. Characterization of normal human brain cultures. Lab Invest 1986; 55 (1): 71-85.

10. Perzelova A, Macikova I, Tardy M, Mraz P, Bizik I. Subpopulation of nestin positive glial precursor cells occur in primary adult human brain cultures. Biologia 2007; 62: 633-640.

11. Sarcar C, Dinda AK, Karak AK, Marthur M, Roy S. Morphological appearance, growht kinetics and glial fibrillary acidic protein (GFAP) expression in primary in vitro explant culture of astrocytic neoplasms. Acta Oncol 1993; 32(3): 301-306. DOI: 10.3109/02841869309093599.

12. MacLeod RAF, Schneider B, Sivakova I, Nagel S, Dirks WG, Mraz P, Kubikova E, Perzelova A. High level EGFR amplification in a newly established glioblastoma cell line: 170-MG-BA. Neoplasma 2019; 66 (1): 109-117. DOI: 10.4149/neo_2018_180427N278.

13. Mac Leod RAF, Dirks WG, Matsuo Y, Kaufman M, Milch H, Drexler HG. Widwspread intraspecies cross-contamination of human tumor cell lines arising at source. Int J Cancer 1999; 83 (4): 555-556.

14. Capes-Davis A, Theodosopoulos G, Atkin I, Drexler HG, Kohara A, MacLeod RA, Masters JR, Nakamura Y, Reid YA, Reddel RR, Freshney RI. Check your cultures! A list of cross-contaminated or misidentified cell lines. Int J Cancer 2010; 127 (1): 1-8. DOI: 10.1002/ijc.25242.

15. Perzelova A, Macikova I, Mraz P, Bizik I, Steno J. Characterization of two permanent glioma cell lines 8-MG-BA and 42-MG-BA. Neoplasma 1998; 45 (1): 25-29. 